\title{
Change blindness, representations, and consciousness: Reply to Nö̈
}

\section{Daniel J. Simons ${ }^{1}$ and Ronald A. Rensink ${ }^{2}$}

${ }^{1}$ Psychology Department and Beckman Institute, University of Illinois, 603 E. Daniel Street, Champaign IL 61820, USA

${ }^{2}$ Departments of Psychology and Computer Science, University of British Columbia, 2136 West Mall, Vancouver BC, V6T 1Z4, Canada

Our recent opinion article [1] examined what change blindness can and cannot tell us about visual representations. Among other things, we argued that change blindness can tell us a lot about how visual representations can be used, but little about their extent. We and others found the 'sparse representations' view appealing (and still do), and initially made the overly strong claim that change blindness supports the conclusion of sparse representations $[2,3]$. We wrote our article because change blindness continues to be taken as evidence for sparse - or even absent - representations, and we used O'Regan and Noë's influential paper [4] as an example. However, as has been noted for some time [5-8], this conclusion is logically flawed: lack of ability need not be caused by lack of representation.

In his letter [9], Noë agreed that change blindness does not logically require sparse representations, but also claimed that the non-representationist view 'does a better job of explaining' change blindness. He further argued that 'the existence of detailed internal representations does not (and could not) explain visual consciousness.' His letter also implied that we had leapt to a non-representationist conclusion based on evidence for change blindness.

However, we never abandoned the idea that representations underlie our conscious experience even though we did argue for sparse representations. In fact, we have argued for ways in which sparse representations could support our subjective impressions [10]. We believe that visual representations are necessary to explain some aspects of conscious experience. For example, people do detect most changes eventually, and conscious change detection requires conscious use of representations. If, according to the non-representationist view, change blindness occurs because representations do not contribute to awareness, then conscious change detection should be impossible.

Given that change blindness is logically consistent with either the presence or the absence of representa- tions and that consciously accessible representations are needed to detect changes, the non-representationist perspective is not objectively better able to explain all of the evidence. Noë also reiterated the claim that the non-representationist perspective predicted change blindness. However, the non-representationist perspective and evidence of change blindness both existed separately for decades before either came to prominence, so the idea that one predicted the other is unsupported.

Change blindness can occur for many reasons other than just from the lack of visual representations $[1,8]$. Noë's commentary leads us to suggest a more tractable question: why do representations sometimes lead to consciousness and other times not? This is an empirical question, and change blindness can contribute to an answer.

\section{References}

1 Simons, D.J. and Rensink, R.A.(2005) Change blindness: Past, present, and future. Trends Cogn. Sci. 9, 16-20

2 Rensink, R.A. et al. (1997) To see or not to see: the need for attention to perceive changes in scenes. Psychol. Sci. 8, 368-373

3 Simons, D.J. and Levin, D.T. (1997) Change blindness. Trends Cogn. Sci. 1, 261-267

4 O'Regan, J.K. and Noë , A. (2001) A sensorimotor approach to vision and visual consciousness. Behav. Brain Sci. 24, 883-975

5 Scott-Brown, K.C. et al. (2000) Comparison blindness. Visual Cogn. 7, 253-267

6 Hollingworth, A. (2003) Failures of retrieval and comparison constrain change detection in natural scenes. J. Exp. Psychol. Hum. Percept. Perform. 29, 388-403

7 Noë ,A.et al. (2000) Beyond the grand illusion: what change blindness really teaches us about vision. Visual Cogn. 7, 93-106

8 Simons, D.J. (2000) Current approaches to change blindness. Visual Cogn. 7, 1-15

9 Noë, A. (2005) What does change blindness teach us about consciousness? Trends Cogn. Sci. 9.

10 Rensink, R.A. (2000) The dynamic representation of scences. Visual Cogn. 7, 17-42 